\title{
O Devir-Criança e a Cognição Contemporânea
}

\author{
Virginia Kastrup ${ }^{1}$ \\ Universidade Federal do Rio de Janeiro
}

\begin{abstract}
Resumo
O texto compara duas concepções acerca das transformações temporais da cognição - aquela das teorias do desenvolvimento, entendida sob o signo da convergência e do fechamento, e aquela baseada nas idéias de Bergson, Deleuze e Guattari, pautada nas idéias de divergência e de diferenciação. Nas teorias do desenvolvimento cognitivo é destacado o conceito de tempo cronológico, o regime de filiação das estruturas e a idéia do ultrapassamento da forma de conhecimento da criança pela do adulto. A partir da concepção bergsoniana de coexistência dos tempos, é trabalhado o conceito de devir-criança de G. Deleuze e F. Guattari, que afirma a tendência inventiva que resta presente enquanto virtualidade em toda formação cognitiva, adulta ou infantil, e caracteriza a cognição contemporânea.

Palavras-chave: Devir-criança; desenvolvimento cognitivo; contemporâneo.
\end{abstract}

Child-Becoming and Contemporary Cognition

Abstract

This paper compared two conceptions of time transformations - one related to theories of development, based on the notions of convergency and closure; and the other related to the theories of Bergson, Deleuze and Guattari, which are based on the ideas of divergency and differentiation. Analysing the theories of cognitive development we call attention to the concept of chronological time, the regimen of structure filiation, and the overcoming of the child's form of knowledge by that of the adult. Guided by the Bergson's idea of coexistence of times, Deleuze and Guattari's concept of child-becoming, which states the inventive tendency that remains in the form of virtuality in every cognitive formation - in adults and children - and that characterizes contemporary cognition are discussed.

Keywords: Child-becoming; cognitive development; contemporary time.

Desenvolvimento Cognitivo: O Tempo Cronológico e a Ordem das Estruturas

No campo dos estudos da cognição, as teorias do desenvolvimento trazem como novidade a introdução do problema do tempo. Trata-se aí do tempo cronológico, que responde pela construção das estruturas cognitivas numa ordem sucessiva. A noção de desenvolvimento assume características próximas e derivadas da noção biológica de evolução, onde as idéiaschave são aquelas de modificação e genealogia (Gould, 1997). Enquanto processo de modificação, a evolução diz respeito às transformações das formas ao longo do tempo; enquanto genealogia, a evolução organiza tais formas em linhagens, por elos de filiação e descendência. As teorias do desenvolvimento cognitivo são pautadas nessas coordenadas; o que as caracteriza é colocar o problema da transformação temporal da cognição em termos de gênese, descendência ou filiação. A criança, bem como o adulto, são entendidos através de suas

Endereço para correspondência: Rua Lopes Trovão, 237, apto. 801 Icaraí, Niterói, Rio de Janeiro, 24220-070. Fone: (21) 6108447. E-mail: vkastrup@nitnet.com.br

Apoio CNPq formas ou estruturas específicas de conhecer. Tais teorias têm ainda como característica tomar o homem adulto como ponto de chegada e termo eminente da série de transformações que têm lugar na cognição da criança. É preciso notar ainda que, autorizando comparações entre as estruturas cognitivas da criança e do adulto a partir dessas coordenadas, a noção de desenvolvimento traz, como uma espécie de contrapeso, a idéia de progresso ${ }^{2}$. Como a colocação do problema das transformações temporais da cognição tem como horizonte a forma adulta de conhecer, a cognição da criança é assombrada pela idéia do déficit. Pergunta-se então o que falta à cognição da criança para chegar à cognição do adulto.

Em outras palavras, nas teorias do desenvolvimento o problema da transformação temporal da cognição é

${ }^{2}$ A associação da idéia de progresso ao conceito de evolução tem hoje recusa terminante de biólogos destacados como S. J. Gould (1997) e F Jacob (1983). Para Gould, a idéia de progresso, que aparece através de referências a uma maior complexidade ou eficiência dos seres mai evoluídos, apenas expressa uma crença ocidental e revela-se como um preconceito social que visa garantir o direito do homem de dominar e explorar o planeta. Por sua vez, Jacob sugere, em lugar do progresso, que o critério da evolução é a abertura do código genético para a aprendizagem, que permite ao organismo expandir seu meio. 
colocado a partir de duas coordenadas. A primeira é horizontal e diz respeito à consideração de sua ocorrência no curso de um tempo histórico, seqüencial e cronológico A segunda é vertical, referindo-se a uma ordem de sucessão marcada pelo progresso. Tomando como exemplo o construtivismo de J. Piaget, verifica-se que as transformações temporais são por certo genealógicas. Cabe à Psicologia explicar a gênese das estruturas cognitivas, sua derivação umas das outras por filiação progressiva durante um processo de construção, ou seja, acompanhar suas transformações da criança ao adulto Encontra-se aí a primeira coordenada: o tempo histórico, sucessivo e seqüencial. Introduzir o tempo é então explica a gênese, a construção das estruturas intelectuais. Traduzindo o problema do tempo como sendo de desenvolvimento cognitivo, Piaget caracteriza a criança por certas estruturas intelectuais que tendem a ser integradas e subordinadas ao modo adulto de conhecer, representado pelas estruturas lógico-matemáticas. A coordenada vertical aparece através da colocação do problema epistemológico, que move a investigação de Piaget. Como o problema é explicar a construção das estruturas que são condição de possibilidade do conhecimento científico, a questão da subjetividade fica definida no âmbito do sujeito epistêmico, e não enquanto singularidade (Moura, 1995). Cabe ressaltar que o problema epistemológico dirige a investigação piagetiana para o comportamento da criança frente a situações lógicas, como tarefas de conservação de quantidades, classificação e seriação. Buscando encontrar as estrutura lógicas da criança, encontra uma pré-lógica ou semi-lógica, que evidencia um déficit ou uma falta, que será ultrapassada pelo modo adulto de conhecer ${ }^{3}$.

O próprio Piaget (1972/1978) destaca que dois aspectos fundamentais do tempo marcam sua abordagem: a duração e a ordem de sucessão. A duração é definida como um intervalo entre as estruturas que são construídas numa ordem fixa, sucessiva e hierárquica. Isto significa que Piaget fala da duração e da transformação temporal da cognição tendo em vista seus pontos de parada relativa - as estruturas cognitivas que caracterizam os estágios do desenvolvimento - e sugere critérios para a comparação entre as capacidades cognitivas correspondentes. Refere-se também a um ultrapassamento dos estágios anteriores pelos estágios posteriores. Segundo seu ponto de vista há progresso efetivo no

${ }_{3}^{3}$ Historiando a entrada de Piaget no campo da Psicologia Cognitiva, Gardner (1987, p. 116) faz referência ao interesse demonstrado pelo então biólogo pelos tipos de "erros" cometidos pelas crinças nos testes de inteligência. desenvolvimento e o processo de assimilaçãoacomodação é o mecanismo invariante que explica tal progresso, respondendo pela construção de novas estruturas, inexistentes nos estágios mais elementares. É pelo acréscimo e integração de estruturas, ao mesmo tempo necessárias e inéditas, que o déficit intelectual da criança é superado.

A infância surge como um longo período de preparação para o modo adulto de conhecer e pensar, caracterizado pelo estágio das operações lógico-formais. A questão é então: o que falta à criança para pensar como um cientista? É notável que a investigação concentra-se em certos setores do conhecimento que se revestem de significação epistemológica. Nesta linha, ganham importância fenômenos cognitivos como a construção dos conceitos de número, velocidade e causalidade. Resulta daí que, na caracterização da cognição da criança, é freqüente a utilização de categorias negativas: inexistência de pensamento, ausência de função simbólica, irreversibilidade das formas, inteligência pré-operatória, pré-lógica, etc. Desenvolver-se é, deste ponto de vista, superar deficiências cognitivas, completar lacunas, deixar para trás estruturas cognitivas imperfeitas que impedem a criança de conhecer como um cientista. A adoção de uma perspectiva epistemológica faz com que o problema de tais transformações seja colocado sob a égide do progresso e da previsibilidade e a investigação da criança reste assombrada pela forma adulta de conhecer. Através de um modelo de desenvolvimento por estágios e em sintonia com a idéia de déficit, o desenvolvimento ultrapassa e deixa para trás a criança, pensada sob a forma de estruturas intelectuais mais rígidas e pobres.

Adotando uma perspectiva histórica, Ariès (1978) teve uma grande importância para o estudo da criança, revelando o modo como a forma infantil de viver, pensar e sentir, foi gestada no período que vai da Idade Média ao século XVIII. Até então, a criança era entendida como um ser diferente apenas quantitativamente do adulto, menor em tamanho e em força. Os estudos da psicologia histórica trazem à luz os alicerces da psicologia do desenvolvimento, ou melhor, as bases históricas da concepção naturalista de criança, que perpassa a psicologia e a pedagogia. A partir de Ariès, evidencia-se que com a formação histórica da noção de criança através de práticas concretas - sobretudo educacionais e familiares - as diferenças quantitativas cedem lugar a diferenças qualitativas. A criança surge como um ser distinto do adulto por sua maneira própria de perceber, conhecer e sentir. No entanto, a diferença quantitativa entre o adulto e a criança, em princípio expulsa, retorna e a questão do déficit intelectual assombrará, como o fantasma 
reminescente de um problema mal resolvido, as teorias do desenvolvimento cognitivo.

Cabe notar ainda que para Piaget o desenvolvimento representa um movimento de fechamento do sistema cognitivo (Kastrup, 1999, 1997a). As estruturas lógicoformais, que coroam o desenvolvimento cognitivo, são definidas como estruturas "extemporâneas" (Piaget, 1970/1978). A possibilidade de serem desestabilizadas, e portanto, modificadas, tende a desaparecer, em função do equilíbrio móvel que possuem. Em outros termos, as formas terminais são ditas atemporais, pois o processo de equilibração majorante, que orienta sua construção, trabalha no sentido de minimizar a instabilidade inicial do sistema cognitivo. O que se revela então é que, tendo como fundamento o modelo da equilibração e como horizonte as estruturas do pensamento lógicomatemático, Piaget pensa as transformações cognitivas sob o signo da convergência e do fechamento. Conclui-se que, sob tal ótica, é progressivamente fechada, ao longo do desenvolvimento, a possibilidade de invenção de outras formas de conhecer, distintas da forma lógicomatemática.

\section{A Coexistência dos Tempos e a Criança como} Virtualidade

Encontra-se em Bergson (1897/1990) uma concepção de tempo distinta do tempo cronológico, e que se apresenta como coexistência de todos os tempos. Tratase de uma concepção que Deleuze (1966/1991) denomina paradoxal, posto que presente, passado e futuro não se sucedem, não se perdem, mas subsistem como coexistência virtual. Pode-se perguntar então o que fica sendo a criança e seu modo próprio de conhecer numa perspectiva filosófica desta natureza. Certamente ela problematiza a noção de desenvolvimento cognitivo por estágios, ao mesmo tempo que abre possibilidades para um conceito positivo de criança, que evita pensá-la como possuidora de um modo de conhecer que é ultrapassado em favor de formas e estruturas mais avançadas. A questão da criança e de seu modo próprio de conhecer não aparece tematizada de forma sistemática na obra de Bergson, o que não impede que se busque em seus textos e em sua concepção de tempo direções para pensar a criança de uma forma positiva, e não sob a égide do déficit ou da falta.

No conceito de evolução criadora encontram-se alguns elementos para pensar a transformação temporal da cognição. Para Bergson (1907/1979) a evolução não segue uma só direção, não possui uma trajetória única, mas desenvolve-se em forma de feixe, de modo rizomático. Enquanto Piaget encontra na vida biológica Psicologia: Reflexão e Crítica, 2000, 13(3), pp.373-382 o fundamento da atividade cognitiva, ou seja, o mecanismo de auto-regulação que assegura a equilibração majorante, Bergson define a vida como força explosiva e suas formas como portadoras de um "equilíbrio instável das tendências". Sob tal perspectiva, toda transformação ao longo da evolução ocorre sob o signo da divergência e da diferenciacão. Segundo Bergson, o élan vital bifurca-se em duas tendência divergentes - tendência repetitiva e tendência inventiva - que se misturam nas formas atualizadas. Toda forma atualizada - e aí podemos ver o caso do sistema cognitivo infantil ou adulto - é um misto de matéria e tempo, guardando uma abertura e encontrando-se sujeito à instabilização.

Por outro lado, existem na obra de Bergson algumas referências que definem a criança como portadora de virtualidade, englobando "em si pessoas diversas que podiam manter-se fundidas juntas porque estavam em estado nascente" (Bergson, 1907/1979, p. 156). A criança é vista ainda como estando, por esta razão, "mais perto da natureza que o adulto" (Bergson, 1934/1979, p. 149). Tais referências dão testemunho de que, para Bergson, há na cognição da criança uma prevalência da tendência temporal e inventiva. Numa filosofia que considera a coexistência das tendências e dos tempos, o modo de conhecer da criança não é algo a ser ultrapassado nem indicativo de um déficit em relação às formas cognitivas terminais, mas um modo de conhecer que assegura a abertura da cognição e persiste como virtualidade. No contexto de uma evolução criadora, onde as tendências divergentes mantêm-se em equilíbrio instável, o "infantill" e o "adulto" coexistem no interior da cognição e a dimensão "infantil" vai se destacar como uma tendência sempre virtual, capaz de fazer divergir as formas e estruturas constituídas.

A coexistência das tendências e dos tempos no plano virtual não impede que se revelem diferenças no plano das formas de conhecer que se atualizam no adulto e na criança. Quando Bergson (1907/1979) afirma que a criança está mais próxima do virtual que o adulto, reconhece que exista alguma perda efetiva, embora circunscrita ao plano dos formas atualizadas, quando as formas adultas assumem uma rigidez que dificulta a continuidade de sua diferenciação. De todo modo, o caminho é outro em relação àquele seguido pelas teorias do desenvolvimento cognitivo pautadas na noção de estágio e na idéia de uma subsunção do modo infantil no modo adulto de conhecer. Bergson coloca: "Na realidade estamos incessantemente fazendo escolhas, e sem cessar também deixamos de lado muitas coisas. O itinerário que percorremos no tempo está juncado dos resíduos de tudo que começávamos a ser, de tudo que poderíamos ter 
vindo a ser. Mas a natureza, que dispõe de um número incalculável de vias, de modo algum se restringe a semelhantes sacrifícios. Ela conserva as tendências que se bifurcaram ao crescer" (Bergson, 1907/1979, p. 156). Para Bergson, haveria sempre "uma" criança no adulto, revelada nos movimentos divergentes da cognição. Embora reconheça que em toda bifurcação há escolha ou seleção de um caminho, o que implica no abandono de outras possibilidades, é inconcebível do ponto de vista bergsoniano a idéia de uma perda irreversível de nossos devires, que asseguram a abertura para o novo e a possibilidade de invenção de novas formas de conhecer. Pois, se este fosse o caso, não perderíamos certos caminhos, mas a possibilidade de sair de nosso modo predominante de conhecer e o desenvolvimento seria um obstáculo à invenção. A partir de tudo isso, fica clara a distinção entre a concepção piagetiana de transformações cognitivas que se dão sob o signo da convergência e do fechamento e a concepção bergsoniana, pautada nas idéias de divergência e de diferenciação. Na segunda maneira de pensat encontram-se elementos para conceber um processo de invenção da cognição que persiste enquanto virtualidade na cognição do adulto, não sendo obstaculizado pelo desenvolvimento.

Em resumo, as teorias do desenvolvimento, como as teorias da evolução, têm como problema explicar a gênese das formas, isto é, o engendramento de umas pelas outras numa ordem sucessiva e seqüencial. No entanto, o tema da transformação temporal da cognição revela-se mais amplo. A Psicologia do desenvolvimento cognitivo descreve um certo regime de transformação tempora da cognição - o regime de filiação - mas não parece que as transformações temporais se limitem a um único regime, nem tampouco que tal regime seja o mais fecundo para pensar a cognição. A atualidade nos lança frente a tantos fatos novos e exigentes de sentido envolvendo a invenção da cognição, que as idéias de gênese, filiação ultrapassamento parecem não dar conta. Talvez as comparações entre a criança e o adulto, baseadas no modelo genético-estrutural e na idéia do déficit nos deixem de mãos vazias para o entendimento da cognição contemporânea.

O Conceito de Devir-Criança de G. Deleuze e F. Guattari

Seguindo a linha bergsoniana de conceber o tempo, G. Deleuze e F. Guattari formulam o conceito de devircriança. Deleuze e Guattari (1980/1997) reconhecem na tese bergsoniana do tempo como virtual, como coexistência de durações distintas e heterogêneas, o princípio de uma realidade própria ao devir. Em consonância com Bergson, o conceito de devir-criança porta a idéia de "uma" criança que persiste no adulto enquanto virtualidade e enquanto condição de divergência e diferenciação da cognição, abrindo caminho para a exploração da dimensão inventiva da cognição. O que se vê aí sugerido é um giro no ponto de partida da investigação, um redirecionamento da atenção, que se desloca então das formas estabilizadas para o movimento que as retira desta condição, ou antes, daquilo que é transformado para aquilo que é o próprio movimento de transformação. Neste caso, é operada uma subversão do modelo genético-estrutural e o devir - empregado como um substantivo - passa ao primeiro plano. A forma-criança, assim como a forma-adulto, serão apenas estados de coisas, pontos de parada, imagens sucessivas, formas dispostas ao longo do regime temporal da gênese e da descendência. Por esta razão, o conceito de devircriança aparece como uma referência importante para um redimensionamento do problema da cognição da criança e, conforme veremos, da cognição contemporânea. Ele indica uma direção para o entendimento das transformações temporais da cognição e também para o que seja a criança, fornecendo uma alternativa concreta para os limites da investigação sobre a invenção pela psicologia (Kastrup, 1999).

Deleuze e Guattari falam da "coexistência de 'durações' muito diferentes, superiores e inferiores à 'nossa', e todas comunicantes" (1980/1997, p.18). A referência a uma espessura temporal onde coexistem durações diversas é bastante diferente do tempo cronológico que constitui a referência das psicologias do desenvolvimento. Ao invés de sustentarem a idéia de formas e estruturas da cognição que obedecem a uma sucessão, onde as da criança são subsumidas pelo adulto, Deleuze e Guattari afirmam: “...'uma’ criança coexiste conosco, numa zona de vizinhança ou num bloco de devir, numa linha de desterritorialização que nos arrasta a ambos - contrariamente à criança que fomos, da qual nos lembramos ou que fantasmamos, à criança molar da qual o adulto é o futuro" (p.92). Falar em devir-criança da cognição é conceber sua operação politemporal, seu movimento entre diversos platôs ou camadas de tempo.

Afirmar uma cognição em devir não é o mesmo que reconhecer sua natureza histórica. Pois o tempo que caracteriza a história é ainda o tempo cronológico dos acontecimentos sucessivos - passado, presente e futuro. O devir não eqüivale a uma transformação temporal que se concretiza no decurso do tempo histórico. Diferentemente, é uma transformação temporal que se dá no presente, caracterizando-se inclusive por operar uma bifurcação em relação às formações históricas, aos 
regimes de funcionamento que caracterizam os estratos. Pode-se dizer que, neste sentido, ele é a designação por excelência do que há de contemporâneo na cognição (Kastrup, 1997b). Não se define como passagem de uma forma a outra, mas sobretudo como movimento que faz tensão com as formas. Deleuze e Guattari cuidam também em distinguir o devir de outras noções com as quais ele poderia ser confundido: identificação, imitação, metamorfose, desenvolvimento ou produção. Esclarecem: "Devir não é certamente imitar, nem identificar-se; nem produzir, produzir uma filiação, produzir por filiação. [...] ele não se reduz, ele não nos conduz a 'parecer', nem 'ser', nem 'eqüivaler', nem 'produzir' (Deleuze \& Guattari, 1980/1997, p.19). Devircriança não é manter com a criança qualquer relação de semelhança, não é imitar a criança. A criança não é a forma na qual nos tornamos estando em devir. Devir-criança não é regredir a um estágio anterior do desenvolvimento, pois o devir não corresponde a uma ordem classificatória nem genealógica (Deleuze \& Guattari, 1980/1997).

$\mathrm{O}$ estudo que toma a cognição em desenvolvimento se empenha em descrever as estruturas que são construídas num fechamento progressivo, mas o estudo da cognição em devir revela uma cognição bifurcante e inventiva. $\mathrm{O}$ devir não se faz por subidas verticais, mas por alianças, desterritorialização e fuga das formas, fazendo com que outros regimes e outros territórios possam vir a ser constituídos. Mas é preciso ter cuidado em não definir o devir por aquilo que ele pode vir a criar. Devir não pode ser confundido com metamorfose. Não é passagem de uma forma a outra, pois o que o caracteriza não são pontos de parada ou de desaceleração, nem um termo final qualquer.

O conceito de devir não visa a explicar as formas. Como foi visto acima, pensar a transformação temporal perspectivada pelo problema da criação de formas é um ponto comum entre as teoria da evolução e do desenvolvimento. Para Deleuze e Guattari (1980/1997) o devir surge, diferentemente, como uma espécie de involucão, pois ele é justamente um movimento de dissolução das formas criadas. São suas palavras: 'Preferimos então chamar de 'involução' essa forma de evolução que se faz entre heterogêneos, sobretudo com a condição que não se confunda involução com regressão. O devir é involutivo, a involução é criadora.” (p.19). Não se trata de regressão a antigas formas. $O$ que define $o$ devir é uma atividade no meio molecular, denso e invisível, que subsiste entre as formas visíveis. A cognição em devir acessa este meio molecular. Não coloca em relação sujeitos e objetos, formas cognitivas e objetos conhecidos, mas é a cognição operando fora das regras, fora das formas. Psicologia: Reflexão e Crítica, 2000, 13(3), pp.373-382
O devir cognitivo não se define por um regime específico, não é apenas um outro regime, mas uma outra dimensão, um outro plano de funcionamento, onde as categorias da representação - sujeito, objeto, leis, formas, estruturas - revelam-se inoperantes.

Deleuze e Guattari (1980/1997) distinguem dois planos: o plano de organização e de desenvolvimento e o plano de consistência ou composição. O plano de organização e de desenvolvimento corresponde às condições de possibilidade das formas visíveis. É um plano "estrutural ou genético, e os dois ao mesmo tempo, plano das organizações formadas em seus desenvolvimentos, plano genético dos desenvolvimentos evolutivos em suas organizações" (p. 54). Ele é condição de desenvolvimento e gênese das formas e também de formação dos sujeitos, mas é um plano transcendente, pois ele próprio não se encontra sujeito à criação. Pode-se concluir que tal plano é aquele que tem sido habitualmente concebido e explorado pelas teorias do desenvolvimento cognitivo. A abordagem estrutural, associada ao caráter teleonômico do desenvolvimento e aos princípios invariantes que fundamentam a transformação temporal das estruturas, dão testemunho desta conclusão.

Por outro lado, Deleuze e Guattari (1980/1997) explicitam que há um outro plano, denominado plano de consistência ou de composição. Trata-se de um plano que não é habitado por formas, mas por forças, linhas, partículas em movimento, que estão aquém das formas existentes e visíveis e, ao mesmo tempo, constituem as condições de criação destas formas, sejam elas sujeitos ou objetos. Trata-se de um plano movente e que caracteriza uma ontologia criacionista. As formas emergem deste plano, distinguindo-se e individuando-se pela composição e agenciamento entre as linhas, movimentos e forças que aí circulam. As formas se distinguem, mas não se separam do plano de composição, sendo nele relançadas e restando sempre imersas no plano de onde emergiram. Isto significa que as formas não possuem limites fechados, mas continuam envolvidas num movimento de criação. Deleuze e Guattari descrevem-no como um plano onde "não há mais absolutamente formas e desenvolvimento de formas; nem sujeitos nem formações de sujeitos. Não há estruturas nem gêneses. Há apenas relações de movimento e repouso, de velocidade e lentidão entre elementos não formados, moléculas e partículas de toda espécie" (p.55). Não há desenvolvimentos, mas agenciamentos e ligações entre partículas que dão consistência às formas. Não se trata de um plano de transcendência, mas de imanência, que não pára de se transformar com aquilo que ocorre nele e com o que se dá a partir dele já que, como dissemos, 
as formas emergentes são nele relançadas, participando da auto-criação permanente do plano de composição. Pode-se dizer ainda que ele indica um funcionamento no sentido contrário ao da estrutura ou da gênese, pois “a forma não pára de ser dissolvida para liberar tempos e velocidades" (p.56), ou seja, a forma não cessa de involuir A consideração da existência deste plano, que é dito também plano molecular, indica uma dimensão ontológica que vai além das formas visíveis. Pode-se dizer ainda que toda transformação das formas passa pelo plano de composição. É justamente por este plano que o devir se define.

Fica evidenciado que, do ponto de vista do devir, a distinção mais importante não é entre o invariante e o histórico, ambos referidos ao plano de organização e de desenvolvimento, mas entre os dois planos descritos acima. Há também comunicação entre estes planos. Podese passar de um a outro, ou seja, as formas podem involuir e entrar em devir, assim como o devir pode configurar formas que tendem a escapam dele. $\mathrm{O}$ devircriança da cognição corresponde à primeira hipótese, enquanto as teorias do desenvolvimento descrevem resultado da segunda. É preciso ter claro ainda que o devir-criança não é exclusivo da forma-criança ou do que Deleuze e Guattari (1980/1997) chamam de criança molar. A criança molar é uma configuração visível, traduzível por certos comportamentos e traços distintivos. Pode-se dizer que é a criança de que tem falado a Psicologia que se refere apenas ao plano de organização e desenvolvimento. No entanto, a criança molecular, que eqüivale ao devir-criança, só pode ser abordada se, além do plano de organização, a Psicologia tomar como referência também o plano de consistência e de composição.

Embora o problema não seja diretamente abordado na obra de Deleuze e Guattari (1980/1997), é preciso identificar algo que seja próprio ao devir-criança, ou seja algo que daria conta de sua especificidade em relação dos demais devires, como o devir-animal e o devirmulher, que também fazem parte do repertório desses autores. A primeira pista é algo que pode ser expresso como uma relação de experimentação mais direta com o meio molecular. No texto $O$ que as crianças dizem? de 1997, Deleuze afirma: “a criança não pára de dizer o que faz ou tenta fazer: explorar os meios, por trajetos dinâmicos, e traçar o mapa correspondente" (p.73). O "meio" evocado não eqüivale ao que a psicologia costuma chamar de ambiente, que é composto por formas e objetos, mas é um meio molecular composto de fluxos materiais, forças tendenciais ou de partículas aquém do limiar da percepção das formas. É a exploração direta deste meio que aparece como primeiro elemento para a caracterização da cognição da criança. Seguindo esta idéia, pode-se avançar um pouco mais pensando que explorar diretamente o meio molecular significa agir desprovido de um programa, entendendo programa em sentido cibernético, como a conjugação de uma memória com um projeto (Jacob, 1983, p.10).

Ora, a assimilação da cognição a um programa foi um dos pontos que marcou o surgimento das ciências cognitivas a partir da segunda metade deste século. A psicologia, desde sempre envolvida com a busca das leis e princípios invariantes da cognição, insere-se a partir desta época num debate transdisciplinar. A noção de programa, junto àquelas de informação, código, processamento simbólico, input-output e outras oriundas da teoria da informação e da cibernética, concorre para a criação da nova versão do cognitivismo - o cognitivismo computacional. Mais uma vez, a ênfase recai sobre o modelo estrutural e é trabalhada agora a equivalência entre a cognição humana e as máquinas cibernéticas. O computador é tomado como um sistema equivalente, ao mesmo tempo que a cognição assume a feição de um software, sendo entendida como portadora de regras gravadas numa memória e que possui um plano que dirige seu funcionamento.

É interessante notar, entretanto, que a consideração de um programa invariante é quase simultaneamente acompanhada da investigação das possibilidades da implementação de modificações do programa (Dupuy, 1996). Em ambas as direções há a pesquisa e o desenvolvimento tecnológico de máquinas que modelizam a cognição. Na primeira direção, que é a do cognitivismo computacional, o modelo buscado é o de um solucionador geral de problemas, materialização da máquina universal de Turing, capaz de realizar qualquer operação desenvolvida pela cognição humana. $\mathrm{Na}$ segunda direção, que é a da abordagem conexionista, o foco incide sobre máquinas capazes de aprender, de formar regras locais frente a tarefas específicas e chegar a configurações que são inseparáveis de sua história de transformações. O conexionismo abandona o sonho de possuir uma máquina com uma inteligência geral, em favor da capacidade de dotá-la de performances flexíveis e específicas, como a categorização e o reconhecimento. Nesse caso, a máquina cognitiva não se define por símbolos e regras, mas pela conexão densa e acentrada de milhares de elementos simples, à maneira das redes neurais, da qual emergem propriedades globais. Para Andler (1987) pesquisas conexionistas como as de Hofstadter (1987) e McClelland, Rumelhart e Hinton (1987) trabalham ao nível de um grão mais fino da 
cognição, renovando a investigação por apontar uma fluidez da cognição humana que as abordagens cognitivistas não consideravam. Ainda nesta linha, Maturana e Varela (1990) desenvolvem trabalhos no que denominam autopoiese dos sistemas vivos, identificando nos aparatos imunológico, neurofisiológico e cognitivo propriedades auto-criadoras. Para estes autores, o fechamento espacial do sistema autopoiético, a partir de uma complexa rede de elementos em interação, coexiste e é condição para sua abertura temporal. O sistema é atingido e entra em transformação não em função de informações provenientes de objetos ou formas dadas, mas de perturbações provocadas por um certo fluxo material. É a partir da perturbação causada por um fluxo de luz que um objeto pode ser visto, é a partir de um fluxo sonoro uma música é reconhecida. Tais pesquisas exploram uma cognição complexa, onde o nível das densas conexões neurais e o das regras emergentes, o nível sub-simbólico e o simbólico coexistem como distintos e indissociáveis, mas irredutíveis um ao outro.

A história da modelização da cognição através das máquinas de informação revela, segundo Varela (s.d.), a ocorrência de uma progressiva substituição do modelo do perito - o expert - pelo modelo da criança. Trata-se de uma observação interessante, pois indica que nesse tipo de investigação a criança é signo de um funcionamento cognitivo desprovido de regras a priori. O que prepondera aí não é a existência de um programa fechado, cuja memória definiria um plano de atividades, mas um programa - ainda um programa - que se definiria por sua capacidade de transformação e aprendizagem de novas configurações. O que se tem em mira é o processo capaz de conduzir à formação de regras. É concebido um movimento, uma instabilidade, uma espécie de caotização do funcionamento cognitivo e as transformações temporais das máquinas conexionistas possuem resultados até certo ponto imprevisíveis. As pesquisas conexionistas vêm buscando trabalhar no limite da modelização, experimentando até onde pode chegar a auto-programação das máquinas cognitivas. $\mathrm{O}$ devircriança talvez reste sendo não modelizável, o não algoritmizável da cognição, mas o conexionismo desperta nosso interesse pelo deslocamento que opera do plano das formas e estruturas, para o plano das conexões em rede, para o plano molecular, onde habita o grão mais fino da cognição.

É preciso avançar na idéia de que o devir-criança da cognição é uma atividade que não é guiada por um programa, que não é controlada por regras prévias que determinariam a ação futura. E uma atividade cognitiva que pode ser dita exploratória ou experimental pois não Psicologia: Reflexão e Crítica, 2000, 13(3), pp.373-382 aguarda pré-requisitos, não espera regras, mas lança-se no presente imediato, possuindo uma velocidade que a faz deslizar e ocupar as brechas que existem entre as formas já conhecidas. Bergson reconhece isto quando afirma que "a criança quer procurar e inventar, sempre à espreita de novidade, impaciente com a regra" (Bergson, 1934/1979, p.149). A impaciência da criança, que não espera um programa ou regras de ação, revela seu devircriança. Parece que se encontra aí uma espécie de duração ou velocidade que permite pensar a especificidade do devir-criança. Esta impaciência com a regra tem como contrapartida uma molecularização da percepção e uma exploração motora mais fina, sintonizada com a fluidez da matéria com a qual entra em contato direto. $\mathrm{O}$ contato fora da regra é acoplamento imediato, porque não se faz através da mediação da representação dos objetos, nem das formas habituais de conhecer e agir. Há aí uma dimensão da subjetividade que transborda das estruturas estabilizadas e que se conecta com uma dimensão do mundo material que também escapa das gestalten bem definidas, das boas formas. É nesta região, onde a cognição se moleculariza e o mundo transborda das formas representadas, que a invenção pode ocorrer.

Completando a afirmação de Deleuze (1997) temos que a criança, enquanto age, vai, "por trajetos dinâmicos, traçar o mapa correspondente" (p. 73). Ora, a criança cartógrafa acessa um meio que transborda o mundo dos objetos. Este é feito de qualidades, substâncias, potências e acontecimentos, que configuram uma multiplicidade movente, instável, sempre longe do equilíbrio, uma espécie de matéria fluida. O mapa que a criança traça, e que configura seu método ou "programa" de ação, confundese então com este meio em movimento que ela explora. O mapa do movimento é por isto mapa em movimento. Suas regras são locais e temporárias e seu meio de ação composto de variações materiais invisíveis, inapreensíveis pelas estruturas históricas e pela representação. Estão no meio do mundo, constituindo o fluxo que corre entre as formas, que transborda dos objetos e das formas conhecidas.

Pode-se constatar que, em suas descrições, Bergson e Deleuze não se limitam à criança molar, mas identificam também a criança molecular. Suas observações tocam no fato da criança carregar consigo menos história e também menos um projeto de ação que o adulto, mas nem por isso aguardar por eles para orientar sua ações. Talvez pela criança viver mais plenamente a experiência que se dá no presente imediato e aí encontrar o impulso que a inclina para o futuro, Bergson e Deleuze tenham se referido a ela para falar dessa dimensão da cognição que 
escorrega por entre as formas e, experimentalmente, acessa intensidades, potências e acontecimentos.

Para Deleuze e Parnet (1977) os devires são sempre aparalelos, fenômenos de dupla captura. O movimento involutivo do devir implica um processo de molecularização das formas percebidas e, ao mesmo tempo, um processo de desmanchamento das formações subjetivas ou de dessubjetivação. O conceito de bloco de devir expressa a idéia de que não nos tornamos alguma coisa sem que esta própria coisa se torne outra, entre ela mesma em devir. Deve-se lembrar que o devir não comunica formas, mas pontos diferenciais. Salta de diferencial em diferencial, sempre em bloco e a comunicação se dá como uma espécie de contágio no plano molecular.

Para esclarecer o conceito de bloco de devir, pode-se retomar um texto de Michel Tournier (1973) que pergunta em seu título: Existe uma literatura infantil?. Nele Tournier apresenta algumas idéias sobre a criança que vão justamente na direção de um deslocamento da colocação do problema de uma forma-criança para um devircriança. Tournier é autor do livro Sexta-feira ou os limbos do Pacifico - uma das inúmeras versões do Robinson Crusoé de Daniel Defoe - que introduz uma modificação até certo ponto desconcertante para aqueles que conhecem a história original. No romance de Tournier o herói, ao final, decide ficar na ilha, ao invés de voltar para a Europa. Tournier relata que escreveu sua versão introduzindo na obra de Defoe referências etnográficas e filosóficas contemporâneas, mas mais tarde julga seu livro exorbitante em referências, com uma filosofia indiscreta e mesmo excessiva. Decide então reescrever a história, dando a ela uma versão mais curta, ágil, leve e límpida, onde a Filosofia viria oculta, ou melhor, clandestina em certos acontecimentos ou em novos episódios narrativos. Segundo Tournier, só ao final, e com surpresa, descobriu que havia escrito um livro para crianças, que denomina então Vendredi ou la vie sawvage. Após enfrentar uma série de problemas para publicar este livro na França - e é bom lembrar que Sexta-feira ou os limbos do Pacifico havia sido publicado por mais de uma dezena de editoras, dentro e fora da França - Tournier resolve perguntar se existe algo que defina um livro como infantil. Com toda radicalidade, interroga se existe, enfim, uma literatura infantil. Sua resposta é que a literatura para crianças é apenas uma obra de arte que alia simplicidade e precisão. Tal literatura pode ser fruída por qualquer um e não exclusivamente por crianças. Tournier aponta tal virtude nas fábulas de la Fontaine, no Alice de Lewis Carrol, nas lendas orientais, nos contos de Grimm e Andersen outros que, como lembra, não foram escritos especialmente para o público infantil. Mas tais escritores escreviam tão bem, sua escrita era tão límpida e concisa que podiam ser entendidos por uma criança.

Tournier (1973) comenta em seguida que o Robinson Crusoé de Defoe produziu enorme quantidade de recriações e avalia que a força desta obra reside exatamente no fato dela criar uma necessidade irresistível de ser reescrita. O contato com a obra literária gera "uma incitação a criar, uma espécie de contágio do processo de criação. Estimula a inventividade dos leitores" (p. 34). A potência da criação surge então como potência de contagiar, incitando o leitor a escrever, gerando um devirescritor no leitor. O interessante é que não ocorre um contágio das formas, mas do processo de criação, gerando a produção de outras obras, inclusive portadoras de outros sentidos. Tournier conclui então que a obra de arte é dotada de uma virtude pedagógica. Lembrando Montaigne, que afirmou que ensinar uma criança não é como encher um vaso, mas como acender uma fogueira, Tournier indica haver uma virtude pedagógica na ficção. É interessante notar como o tema da aprendizagem surge ressignificado a partir de uma perspectiva criacionista e artística. De acordo com a perspectiva ambientalista, aprendizagem significava aquisição de respostas ou de regras que assegurariam a adaptação a um meio previamente dado. No sentido indicado por Tournier, que remonta a Montaigne, a aprendizagem surge como processo de criação de si e do mundo, de forma recíproca e indissociável.

É interessante notar também como, de acordo com tal perspectiva, a aprendizagem se dá num bloco de devir. No exemplo enfocado acima, a leitura do texto provoca no leitor um devir-criança, convoca a criança que subsiste contemporânea com as formas adultas de conhecer. Pois ela começa quando se acessa algo que não estava nas palavras, nas frases, ou no texto formatado pelo escritor, mas nas suas entrelinhas, naquilo que vinha clandestino, invisível aos olhos que só vêem antigas formas, que são presas de automatismos recognitivos. Entretanto, os olhos mais acurados, que possuem uma percepção mais fina, acessam esta outra dimensão do texto. Esta dimensão da cognição que escorrega por entre as formas e, experimentalmente, acessa as intensidades, potências e acontecimentos do texto é o devir-criança. Aí a cognição age sem programa, e exatamente por isto toca naquilo que não poderia ser previsto, nem pelo próprio autor. $\mathrm{O}$ contato com o texto literário promove devires cognitivos os mais diversos. No caso destacado por Tournier (1973), o devir-criança se transmuta num devir-escritor. Mas o escritor em que se devém não é o mesmo que escreveu o livro que se lê, mas um outro, que escreve um outro livro, 
que continua a afetar e contagiar aquele que aprendeu não a ler, simplesmente, mas a ler deixando-se levar por um devir-criança, isto é, sem programa, explorando, e deixando-se contagiar pelo movimento de criação que habita o texto.

É preciso atentar ainda que há um devir-criança, um devir-mulher, um devir-animal, mas "não há devirhomem”. Há um devir-criança do homem, mas não há um devir-homem da criança (Deleuze \& Guattari, 1980/ 1997, p. 89). Este é outro ponto importante a ser marcado, pois desfaz possíveis equívocos na interpretação das teorias do desenvolvimento. Para Deleuze e Guattari o homem é uma figura molar, uma forma. Sua entrada em devir resulta justamente da possibilidade de acessar o plano molecular, mas isto só se faz através do devircriança, do devir-mulher, do devir-animal, ou seja, das outras velocidades e lentidões que se encontram no plano de composição. Encontra-se neste ponto uma perspectiva diametralmente oposta àquela adotada pelas teorias do desenvolvimento cognitivo. Pensar o devir-criança do homem em lugar de estudar a criança tendo como ponto de chegada e como forma eminente na série genealógica das estruturas cognitivas a forma do homem adulto, eis aí a inversão radical que se evidencia no confronto entre estas duas abordagens da cognição. No salto de um plano a outro, as teorias do desenvolvimento adotam o modelo da territorialização. As perturbações e instabilidades que têm lugar no sistema cognitivo, constituem movimentos de desterritorialização relativa, pois desembocam em compensações e apenas ganham sentido quando constituem um retorno a um equilíbrio. Mesmo quando este equilíbrio assume a feição de um equilíbrio processual, a ênfase é nas formas territorializadas. Em contrapartida, o conceito de devir-criança orienta a investigação para o movimento de desterritorialização, fuga e desmanchamento das formas. Por isto o devir-criança é dito movimento de desterritorialização absoluta. Tomálo como ponto de partida significa deixar de pensar o processo de transformação temporal através das formas que dele resultam, ou seja, o processo através do produto, o movimento pelo parado, a invenção pelo invento.

A complexidade da cognição infantil advém de duas dimensões - molar e molecular - irredutíveis uma à outra. Trabalhos em Psicologia do Desenvolvimento identificaram estruturas ou formas molares que correspondem à territorialização da cognição infantil. Tais formas dotam a cognição de uma estabilidade relativa, e sem elas o devir-criança, enquanto movimento de desterritorialização, não seria efetivado. É preciso que existam formas, pois não há devir senão das formas e encontramos aí o lugar dos estudos da Psicologia do Psicologia: Reflexão e Crítica, 2000, 13(3), pp.373-382 desenvolvimento. No entanto, a cognição da criança, por sua natureza, exige uma psicologia igualmente complexa que, além das formas e estruturas da cognição infantil, acesse o devir-criança e que, ao invés de basear-se apenas no plano de desenvolvimento e organização, busque acolher em seu campo de investigação os movimentos involutivos, dissipativos, de desmanchamento das formas constituídas e que evidenciam, de maneira às vezes sutil, a dimensão molecular da cognição infantil e seu enraizamento no plano de consistência ou composição.

\section{A Cognição Contemporânea}

A atenção à atualidade faz ver que as transformações da cognição não se restringem a uma sucessão linear nem a um caminho privilegiado. Retraçar a marcha em direção à forma homem adulto de conhecer faz da criança uma forma negativa, prestes a ser ultrapassada pelo adulto. Se, ao contrário, busca-se o devir-criança - e isto tanto na forma-criança quanto na forma-homem - atinge-se o contemporâneo no seio da cognição. A criança, como o adulto, experimenta na atualidade novas formas de conhecer e viver, mas o devir-criança remete às pontas de presente que subsistem na cognição. As idéias de contemporaneidade e atualidade não se referem a um momento histórico, mas a uma dimensão experimental, de transformação e movimento que o presente encarna (Kastrup, 1997b). Nesta linha, a investigação da cognição contemporânea não pode se esgotar na identificação das novas formas, mas deve buscar apreender a raiz da transformação temporal, o sempre novo que se dá na cognição por sua dimensão experimental. O conceito de devir-criança surge então como ponto de onde se deve partir para a investigação da cognição contemporânea.

$\mathrm{Na}$ cognição contemporânea as estruturas, as formas, ou mesmo as formações históricas existentes coexistem com os devires que vêm se esboçando. Amplia-se o domínio da Psicologia entendendo a atualidade como um campo movente, onde certos regimes de funcionamento cognitivo ou estratos históricos constituídos encontram-se em tensão com a processualidade ou inventividade da cognição. Deste ponto de vista, o presente revela-se espesso, politemporal, estendendo-se sobre o passado e o futuro. Possuindo uma espessura temporal, o presente não sucede o passado nem precede o futuro, mas faz coexistirem estes tempos. Pode-se dizer que a experimentação coexiste com a história e o presente com o passado, apontando para o futuro. Como afirma Castro (1992) é preciso que a Psicologia do Desenvolvimento explore outras concepções de tempo além do tempo cronológico. Fecundando os estudos das psicologias do 
desenvolvimento com as filosofias do virtual e trabalhando com a idéia da coexistência dos tempos, pode-se encontrar na criança um modo positivo de conhecer, encarnação sempre atual da tendência inventiva da cognição.

As transformações são notáveis no que diz respeito às formas de viver a infância na atualidade. A precocidade dos comportamentos sexuais, os atos de violência praticados por crianças, as agendas cheias de compromissos da criança das classes média e alta, todos estes fatos, amplamente divulgados pela imprensa nacional e internacional, levam a que se fale numa abreviação mesmo num fim da infância nos dias atuais. Por certo não encontraremos a criança contemporânea se estivermos tomados pela perspectiva da criança molar e pela nostalgia das antigas formas da subjetividade infantil. Por outro lado, procurando identificar onde está a criança contemporânea vemos que ela se mantém viva no devircriança. Encontramo-la na criança sem-terra, nos meninos de rua, na criança superprotegida pela babá eletrônica ou pela parafernália tecnológica. Em resumo, o conceito de devir-criança evita a miopia causada pelo pressuposto da identidade e a nostalgia de uma infância naturalizada, ao mesmo tempo que localiza a criança contemporânea. E ilustrativo evocar uma imagem vigorosa que abre o livro de fotografias Terra de Sebastião Salgado. Três meninos habitantes do sertão do Ceará contemplam sua obra: uma fazenda construída de ossos de animais mortos, provavelmente vítimas da seca. O cemitério torna-se rebanho e a morte é transmutada em vida no campo. Transmutação feita de restos, restos que dão corpo ao desejo de invenção de um outro mundo. A pergunt retorna: o que, na conduta cognitiva desses meninos, dá indícios do infantil? Não é a forma que interessa, pois a marca maior do infantil, o que faz delas ainda crianças é por certo um devir cognitivo. A força da imagem de Sebastião Salgado deve-se ao fato de que, na contemplação do brinquedo construído, da obra de arte, expressa-se a força não mensurável do devir criança.

\section{Referências}

Andler, D. (1987). Progrès en situation d'incertitude. Le Débat - Émergence du Cognitif, 47, 5-25.

Ariès, P. (1978). História social da criança e da família. Rio de Janeiro: Zahar. Bergson, H. (1979). A evolução criadora. Em Coleção Os Pensadores (pp.

153-205). São Paulo: Abril Cultural. (Original publicado em 1907)
Beroson, H. (1979). O pensamento e o movente - Introdução. Em Colecãa Os pensadores (pp. 99-151). São Paulo: Abril Cultural. (Original publicado em 1934)

Bergson, H. (1990). Matéria e memória. São Paulo: Martins Fontes. (Original publicado em 1897)

Castro, L. R. (1992). Desenvolvimento humano: Uma perspectiva paradigmática sobre a temporalidade. Psicologia: Reflexão e Crítica, 5, 99-110.

Changeux, J. P. \& Danchin, A. (1978). Aprender por estabilizacão das sinapses ao curso do desenvolvimento. Em E. Morin \& M. PiattelliPalmarini (Orgs.), $O$ cérebro bumano - $A$ unidade do bomem (pp. 55-85). São Paulo: Cultrix-EDUSP.

Deleuze, G. \& Parnet, C (1977). Dialogues. Paris: Flammarion.

Deleuze, G. \& Guattari, F. (1997). Devir intenso, devir animal, devir imper-

ceptivel. Em G. Deleuze \& F. Guattari (Orgs.), Mil platôs (Vol. 4, pp.11-
colir ceptível. Em G. Deleuze \& F. Guattari (Orgs.), Mil platôs (Vol. 4, pp.11-
113). Rio de Janeiro: Ed. 34 Letras. (Original publicado em 1980)

Deleuze, G. (1997). O que as crianças dizem? Em G. Deleuze (Org.), Crítica e clinica (pp. 73-79). Rio de Janeiro: Ed. 34 Letras.

Deleuze, G. (1966/1991). Le Bergsonisme. Paris: PUF.

Dreyfus, H. (1992). La portée philosophique du connexionnisme. Em D. Andler (Org.), Introduction aux sciences cognitives (pp. 352-373). Paris: Gallimard.

Dupuy, J. P. (1996). Nas origens das ciências cognitivas. São Paulo: UNESP.

Gardner, H. (1987). The mind's new science. New York: Basic Books.

Gould, S. J. (1997). Três aspectos da evolução. Em J. Brockman \& K. Matson (Orgs.), As coisas são assim - pequeno repertório cientifico do mundo que nos son (Orgs.), As coisas são assim - pequeno repertório científín do
cerca (pp. 95-100). São Paulo: Companhia das Letras.

Hofstadter, D. (1987). Cognition, subcognition: sortir du rêve de Boole. Le Débat - Émergence du Cognitif, 47, 26-44.

Jacob, F. (1983). A logica da vida. Rio de Janeiro: Graal.

Kastrup, V. (1997a). Sabedoria e ilusões de um cientista - Uma resposta às críticas de Piaget a Bergson. Revista do Departamento de Psicologia da UFF, $9(2 / 3), 38-50$.

Kastrup, V. (1997b). A cognição contemporannea e a aprendizagem inventiva. Arquivos Brasileiros de Psicologia, 49(4), 108-122.

Kastrup, V. (1999). A invenção de si e do mundo - Uma introducão do tempo e do coletivo no estudo da cognicão. Campinas, São Paulo: Papirus.

Maturana, H. \& Varela, F. (1990). El arbol del conocimiento. Madrid: Debate.

(1987). Une nourelle approche de la cognition: Le conexionnisme. Le Débat Émergence du Cognitif, 47, 45-64.

Mehler, J. (1978). Conhecer por desaprendizagem. Em E. Morin \& M. Piattelli-Palmarini (Orgs.), O cérebro bumano - A unidade do homem (pp. 2335). São Paulo: Cultrix-EDUSP.

Moura, M. L. S. (1995). A epistemologia genética e a prática pedagógica. Cadernos de Psicologia, 3, 39-69.

Piaget, J. (1978). A epistemologia genética. São Paulo: Abril Cultural. (Original publicado em 1970)

Piaget, J. (1978). Problemas de psicologia genética. São Paulo: Abril Cultural. (Original publicado em 1972)

Piaget, J. \& Inhelder, B. (1978). A psicologia da crianca. São Paulo - Rio de Janeiro: Difel. (Original publicado em 1972)

Tournier, M. (1973). Existe uma literatura infantil? O Correio da UNESCO, $1,33-34$.

Varela, F. (s.d). Conbecer - As ciências cognitivas: Tendências e perspectivas. Lisboa: Instituto Piaget.

Recebido em 28.07.1999 Primeira revisão em 14.10 .1999 Segunda revisão em 17.11 .1999 Aceito em 19.01.2000

Sobre a autora:

Virgínia Kastrup é Doutora em Psicologia pela Pontifícia Universidade Católica de São Paulo, Pesquisadora do CNPq e Professora do Instituto de Psicologia, onde leciona no Curso de PósGraduação em Psicologia da Universidade Federal do Rio de Janeiro. 